\title{
Requirements for Cerebrovascular Surgery in Comprehensive Stroke Centers in South Korea
}

\author{
Tackeun Kim, M.D., ${ }^{1}$ Chang Wan Oh, M.D., Ph.D., ${ }^{1}$ Hyeon Seon Park, M.D., Ph.D., ${ }^{2}$ Kunsei Lee, M.D., Ph.D., ${ }^{3}$ \\ Won Kyung Lee, M.D., Ph.D., ${ }^{4}$ Heeyoung Lee, M.D., Ph.D. ${ }^{5}$ \\ Department of Neurosurgery,' Seoul National University Bundang Hospital, Seongnam, Korea \\ Department of Neurosurgery, ${ }^{2}$ Inha University Hospital, Incheon, Korea \\ Department of Preventive Medicine, 3 School of Medicine, Konkuk University, Seoul, Korea \\ Department of Social and Preventive Medicine, ${ }^{4}$ Inha University School of Medicine, Incheon, Korea \\ Center for Preventive Medicine and Public Health, ${ }^{5}$ Seoul National University Bundang Hospital, Seongnam, Korea
}

Objective : Cerebrovascular disease (CVD) was the third most common cause of death in South Korea in 2014. Evidence from abroad suggests that comprehensive stroke centers play an important role in improving the mortality rate of stroke. However, surgical treatment for CVD is currently slightly neglected by national policy, and there is still regional imbalance in this regard. For this reason, we conducted a survey on the necessity of, and the requirements for, establishing regional comprehensive cerebrovascular surgery centers (CCVSCS).

Methods : This investigation was performed using the questionnaire survey method. The questionnaire was consisted with two sections. The first concerned the respondent's opinion regarding the current status of demand and the regional imbalance of cerebrovascular surgery in South Korea. The second section asked about the requirements for establishing regional CCVSCs. We sent the questionnaire to 100 board members of the Korean Society of Cerebrovascular Surgeons.

Results : Most experts agreed that cerebrovascular surgery patients were concentrated in large hospitals in the capital area, and $83.6 \%$ of respondents agreed that it was necessary to alleviate the regional imbalance of cerebrovascular surgery. With regards to personnel, over $90 \%$ of respondents answered that at least two neuro-vascular surgeons and two neuro-interventionists are necessary to establish a CCVSC. Regarding facilities, almost all respondents stated that each CCVSC would require a neuro-intensive care unit and hybrid operating room. The survey asked the respondents about 13 specific neurovascular surgical procedures and whether they were necessary for a regional CCVSC. In the questions about the necessity of cerebrovascular surgical equipment, all seven pieces of equipment were considered essential by all respondents. A further five pieces of equipment were considered necessary on site: computed tomographic angiography, magnetic resonance angiography, conventional angiography, surgical microscope, and surgical navigation. Our results may provide a basis for future policy regarding treatment of cerebrovascular disease, including surgery.

Conclusion : Raising the comprehensiveness of treatment at a regional level would lower the national disease burden. Policies should be drafted regarding comprehensive treatment including surgery for cerebrovascular disease, and related support plans should be implemented.

Key Words : Cerebrovascular disorders · Patient transfer $\cdot$ Health resources.

- Received : August 3, 2017 • Accepted : September 22, 2017

- Address for reprints : Heeyoung Lee, M.D., Ph.D.

Center for Preventive Medicine and Public Health, Seoul National University Bundang Hospital, 82 Gumi-ro, 173beon-gil, Bundang-gu, Seongnam 13620, Korea

Tel : +82-31-787-3986, Fax : +82-31-787-4059, E-mail : wanderingstone@gmail.com

This is an Open Access article distributed under the terms of the Creative Commons Attribution Non-Commercial License (http://creativecommons.org/licenses/by-nc/4.0) which permits unrestricted non-commercial use, distribution, and reproduction in any medium, provided the original work is properly cited. 


\section{INTRODUCTION}

After cancer and heart disease, cerebrovascular disease (CVD) was the third most common cause of death in South Korea in $2014^{3}$. Moreover, the stroke-related mortality rate in South Korea was 119 per 100000 population, which was higher than the average (96 per 100000) among the member states of the Organization for Economic Co-operation and Development ${ }^{6}$. Therefore, as a part of the national health plan 2020, the South Korean government has established targets for CVD management. One of these targets focuses on preventing, or lowering the incidence of, CVD; the other concerns improving treatment for patients with $\mathrm{CVD}^{5}$.

Evidence from abroad has shown that CVD-related mortality can be improved by establishing comprehensive stroke centers (CSCs) for acute ischemic stroke ${ }^{2)}$. Operating CSCs can also improve prognosis in patients who have suffered a hemorrhagic stroke $e^{4)}$. Indeed, to improve prognosis in acute stroke patients, it is of utmost importance that appropriate surgical treatment be carried out promptly. Therefore, as another essential strategy in CVD management, policymakers should consider reinforcing surgical capabilities. However, in South Korea, stroke patients are concentrated in large hospitals, especially in the capital area. This has led to qualitative, as well as quantitative, differences among the regional medical institutes.

In the current review, we aimed to investigate the opinions of South Korean cerebrovascular surgeons regarding this regional imbalance, as well as to establish — on the basis of expert opinion-preliminary lists of requirements for establishing comprehensive cerebrovascular surgical centers (CCVSCs).

\section{MATERIALS AND METHODS}

This investigation was performed using the questionnaire survey method. The questionnaire was composed by the authors and consisted of two sections. The first concerned the respondent's opinion regarding the current status of demand and the regional imbalance of cerebrovascular surgery in South Korea. The second section asked about the requirements for establishing regional CCVSCs. After meticulously reviewing the literature concerning CSC management, we divided the requirements for CCVSCs into four main domains: personnel, facilities, management programs, and operation capabilities. With regards to personnel, the questions asked about the necessities and minimal requirements for neurosurgical specialists (neuro-vascular surgeons and neuro-interventionists), neurosurgical residents, and physicians' assistants. Regarding facilities, the questions were divided into two subsections : one addressed the neurologic intensive care unit (neuro-ICU), while the other focused on the hybrid operating room (HOR). Concerning the management program, the questionnaire asked about the necessity of a stroke database and about the stroke clinical pathway.

Furthermore, we asked the respondents how quickly they believed surgical services should be provided (neurological surgery and related procedures such as diagnostic techniques). Specifically, we asked about 13 surgical procedures (ventricular drainage, hematoma evacuation by craniotomy, clipping of aneurysms, coiling of aneurysms, microsurgical excision of cerebral arteriovenous malformation [AVM], embolization of AVM, radiosurgery for AVM, extracranial-intracranial direct bypass, extracranial-intracranial indirect bypass, carotid endarterectomy, intra-arterial thrombolysis or thrombectomy, angioplasty and stenting, and decompressive hemicraniectomy) and seven pieces of equipment (computed tomographic $[\mathrm{CT}]$ angiography, magnetic resonance $[\mathrm{MR}]$ angiography, biplane digital subtraction angiography, single photon-emission $\mathrm{CT}$, quantitative MR angiography, surgical microscope, and navigation system). The answers consisted of four categories : 1) it should be provided on-site, 2) it should be provided on an "on-call" basis, 3) it should be provided as an elective surgery, and 4) it is not necessary.

We sent the questionnaire to 100 board members of the Korean Society of Cerebrovascular Surgeons representatives. The electronic survey system was used to collect data from April to June 2015. During the investigation period, 55 of the 100 survey targets answered the questionnaire in at least one domain.

\section{RESULTS}

\section{Recognition of the current status of cerebrovas- cular surgery in South Korea}

Most respondents predicted that the number of patients with CVD will increase, because the population is aging, and 
because the number of patients undergoing surgery for CVD has increased in recent year.

With regards to regional imbalance, most of those surveyed believed that patients undergoing cerebrovascular surgery were concentrated in large hospitals. Furthermore, there were local differences regarding this opinion, and many responded that, even within the Seoul area, medical specialists are limited to the large hospitals. The most commonly proffered reason for this concentration within large hospitals was that the patients' choice of medical institution was being respected. The second most common response was that accessibility had improved due to infrastructure development.

Respondents tended to disagree more about the qualitative problem of regional medical institutions : only $18.5 \%$ believed there was a shortage of regional medical institutions. Accessibility and regional imbalance are not currently at a critical level, according to the respondents. However, it may be a problem that about $30 \%$ of patients still use medical institutions outside the jurisdiction of their local residence. This figure is likely to continue rising; however, it is critical that there be fewer cerebrovascular surgery patients whose management for relapse and complication takes place outside their local region. In the case of non-invasive procedures, many patients travelled to different jurisdictions, especially if their complaint was not an emergency.

In the questions regarding whether policy changes were necessary to alleviate the regional imbalance of cerebrovascular surgery, an overwhelming proportion (83.6\%) of respondents answered in the affirmative, and the proportion was higher in the regions than in the Seoul area. Furthermore, many respondents $(87.2 \%)$ believed that government policy to promote regional hospitals was also necessary; again, there was a big gap between the regions and Seoul in this regard. To illustrate, only $8.3 \%$ of the respondents in Seoul believed that policy was "critically necessary," while the equivalent proportion in the regions was 36.4\%; in Gyeonggi-Incheon, it was $57.1 \%$ - showing that the difference in opinions was great.

In the more detailed, methodological questions, a high proportion of respondents believed that it was inappropriate to limit the right of patients to choose their own medical institution. Furthermore, 58.3\% thought that limiting the amount of surgery in the large Seoul hospitals would be inadequate to solve the problem; in the Seoul area, $75.0 \%$ were of this opinion, showing more differences of opinion between the regions and the capital. Most respondents (98.2\%) opined that it would be appropriate for the government to promote regional cerebrovascular centers; $100 \%$ were of this opinion in the regions.

With regards to certifying regional cerebrovascular surgery centers on a national scale, $70.4 \%$ of respondents agreed, with somewhat lower agreement (66.7\%) in Seoul. Meanwhile, $46.4 \%$ of respondents agreed that consortium surgery centers should be merged, with a somewhat higher agreement (50.0\%) in Seoul. Eighty percent of respondents agreed that a certification system should be used to strengthen regional hospitals; again, this proportion was higher in the regions than in Seoul. Among the support plans mentioned, most respondents placed highest priority on promoting requests for manpower; that is, more neurosurgeons.

\section{Personnel, facilities, and management programs}

Regarding personnel, facilities, and management, the supply and demand of manpower was a greater problem than resources such as surgery facilities and equipment. Neurosurgical specialists and residents are necessary manpower in emergency surgery.

Most respondents agreed that specialized personnel were necessary for regional CCVSCs. In particular, $96.2 \%$ of respondents answered that a neuro-vascular surgeon is necessary, and most thought that two neuro-vascular surgeons were necessary. Similarly, $94.3 \%$ of respondents agreed that a neuro-interventionist was necessary, and most thought that two neuro-interventionists were necessary. Furthermore, $84.9 \%$ of respondents agreed that three general neurosurgeons were necessary. Regarding neurosurgical residents and physicians' assistants, $88.7 \%$ and $82.4 \%$ of respondents thought them necessary, respectively.

With regards to facilities, almost all respondents (90.4\%) opined that a neuro-ICU and HOR are required for a CCVSC, and most answered that 10 neuro-ICU beds were required. Similarly, almost all respondents agreed that management programs, such as a stroke database (81.1\%) and stroke clinical pathways (86.8\%), were necessary (Table 1).

\section{Surgical capabilities and equipment}

Over $90 \%$ of respondents believed that 12 surgical procedures are necessary for establishing regional CCVSCs, among 13 cerebrovascular surgical procedures that were asked about 
in the survey; however, only $78 \%$ or respondent believed that AVM radiosurgery was necessary. Over 60\% responded that the following surgeries are needed immediately on site: ventricular drainage, craniotomy for hematoma removal, intra-

Table 1. Personnel and facilities necessary to establish comprehensive cerebrovascular surgical centers

\begin{tabular}{|c|c|c|c|}
\hline \multirow{2}{*}{ Item } & \multicolumn{2}{|c|}{ Necessity } & \multirow{2}{*}{$\begin{array}{l}\text { Minimal requirement } \\
\text { (most frequent answer) }\end{array}$} \\
\hline & Yes (\%) & No (\%) & \\
\hline \multicolumn{4}{|l|}{ Personnel } \\
\hline Neurosurgeon & 84.9 & 15.1 & 3 \\
\hline Neuro-vascular surgeon & 96.2 & 3.8 & 2 \\
\hline Neuro-vascular interventionist & 94.3 & 5.7 & 2 \\
\hline Neurosurgical resident & 88.7 & 11.3 & 4 \\
\hline Physician assistant & 82.4 & 17.6 & 2 \\
\hline \multicolumn{4}{|l|}{ Facilities } \\
\hline Neuro intensive care unit & 90.4 & 9.6 & 10 beds \\
\hline Hybrid operating room & 90.4 & 9.6 & \\
\hline \multicolumn{4}{|l|}{ Programs } \\
\hline Stroke database & 81.1 & 18.9 & \\
\hline Stroke clinical pathways & 86.8 & 13.2 & \\
\hline
\end{tabular}

Table 2. The necessity of items associated with cerebrovascular surgery

\begin{tabular}{|c|c|c|c|c|}
\hline & \multicolumn{4}{|c|}{ Response rate (\%) } \\
\hline & On site & On call & Elective & Not necessary \\
\hline \multicolumn{5}{|l|}{ Surgery } \\
\hline Ventricular drainage & 86.3 & 9.8 & 0.0 & 3.9 \\
\hline Craniotomy for hematoma removal & 64.7 & 33.3 & 0.0 & 2.0 \\
\hline Clipping of aneurysms & 34.6 & 59.6 & 3.85 & 1.9 \\
\hline Coiling for aneurysms & 33.3 & 60.8 & 3.9 & 2.0 \\
\hline AVM microsurgical excision & 13.7 & 37.3 & 47.1 & 2.0 \\
\hline AVM embolization & 13.7 & 39.2 & 45.1 & 2.0 \\
\hline AVM radiosurgery & 2.0 & 6.0 & 70.0 & 22.0 \\
\hline EC-IC direct bypass surgery & 14.0 & 46.0 & 32.0 & 8.0 \\
\hline EC-IC indirect bypass surgery & 12.0 & 12.0 & 66.0 & 10.0 \\
\hline Carotid endarterectomy & 6.0 & 26.0 & 60.0 & 8.0 \\
\hline Intra-arterial thrombolysis/thrombectomy & 62.7 & 35.3 & 0.0 & 2.0 \\
\hline Angioplasty and stenting & 27.5 & 39.2 & 31.4 & 2.0 \\
\hline Decompressive hemicraniectomy & 60.8 & 35.3 & 2.0 & 2.0 \\
\hline \multicolumn{5}{|l|}{ Equipment } \\
\hline CT angiography & 92.2 & 7.8 & 0.0 & 0.0 \\
\hline MR angiography & 74.5 & 23.5 & 2.0 & 0.0 \\
\hline Conventional angiography & 66.7 & 33.3 & 0.0 & 0.0 \\
\hline SPECT & 12.0 & 26.0 & 62.0 & 0.0 \\
\hline Quantitative MR angiography & 14.0 & 30.0 & 42.0 & 14.0 \\
\hline Surgical microscope & 88.2 & 11.8 & 0.0 & 0.0 \\
\hline Surgical navigation & 68.0 & 24.0 & 6.0 & 2.0 \\
\hline
\end{tabular}

AVM : arteriovenous malformation, EC-IC : extracranial-intracranial, CT : computed tomography, MR : magnetic resonance, SPECT : single photonemission CT 
arterial thrombolysis/thrombectomy, and decompressive hemicraniectomy. In addition, many believed that clipping and coiling of aneurysms should be available on call. As for the other seven procedures, most respondents believed that they should be provided electively on working days or weekdays (Table 2).

In the questions about the necessity of cerebrovascular surgical equipment, all seven pieces of equipment were thought to be essential. Specifically, five pieces of equipment are needed immediately on site : CT angiography, MR angiography, conventional angiography, surgical microscope, and surgical navigation. Furthermore, the majority opinion was that single proton emission computed tomography (62.0\%) and quantitative MR angiography (42.0\%) should be provided electively on working days or weekdays; however, $30.0 \%$ believed that MR angiography should be available on call (Table 2).

\section{DISCUSSION}

In another unpublished survey on the current status and problems of regional cardio-cerebrovascular disease management, about $30 \%$ of patients with cerebrovascular disease moved to another region for treatment. Several approaches can be taken to answering the question of why about 30\% of patients still cannot access cerebrovascular surgery within their own region. Many cases of non-emergency surgery are still transferred to larger hospitals in Seoul; another survey involving the general population suggested that it was highly dependent on the ability of the doctor, and the hospital. In South Korea, centralization of medical services within the Seoul metropolitan area is a major problem, as stated above. According to the experts' response in this study, cerebrovascular surgery-related resources varied widely across each re-

Table 3. Proposed recommendations for a comprehensive stroke center by the brain attack coalition

\begin{tabular}{|c|c|c|}
\hline & Essential & Optional \\
\hline Personnel & $\begin{array}{l}\text { Neurologist } 24 / 7 \\
\text { Multidisciplinary stroke team (NR, NS, RM, neuroradiology, } \\
\text { nurse) }\end{array}$ & $\begin{array}{l}\text { Stroke faculty } \\
\text { NS and vascular surgeon } \\
\text { Intervention radiologist } \\
\text { Rehabilitation staff } \\
\text { Emergent department staff } \\
\text { Stroke fellow } \\
\text { Stroke advanced practice nurse } \\
\text { Stroke coordinator }\end{array}$ \\
\hline Protocol and program & $\begin{array}{l}\text { Stroke CP } \\
\text { Staff education program } \\
\text { Patient education program }\end{array}$ & $\begin{array}{l}\text { Community education QI activity } \\
\text { Program QI } \\
\text { Stroke DB/registry } \\
\text { Stroke center network } \\
\text { Research activity } \\
\text { Anticoagulation clinic }\end{array}$ \\
\hline Diagnosis & $\begin{array}{l}\text { Brain CT 24/7 } \\
\text { MRI with diffusion } \\
\text { CTA/MRA } \\
\text { Lab service }\end{array}$ & $\begin{array}{l}\text { Transfemoral cerebral angiography } \\
\text { Perfusion CT/MR, SPECT/PET } \\
\text { Transcranial/carotid Doppler } \\
\text { Echocardiography }\end{array}$ \\
\hline Treatment & $\begin{array}{l}\text { IV-tPA 24/7 } \\
\text { Antithrombotic therapy } \\
\text { Vital sign control } \\
\text { ICP control }\end{array}$ & $\begin{array}{l}\text { IA thrombolysis } \\
\text { Carotid stent/angioplasty } \\
\text { Cerebral aneurysm surgery } \\
\text { Carotid endarterectomy } \\
\text { Hemicraniectomy } \\
\text { Hematoma evacuation }\end{array}$ \\
\hline Facility & $\begin{array}{l}\text { Emergent department } \\
\text { Stroke admission ward }\end{array}$ & $\begin{array}{l}\text { Stroke unit } \\
\text { Rehabilitation unit } \\
\text { ICU } \\
\text { Stroke outpatient clinic }\end{array}$ \\
\hline
\end{tabular}

NR : neurology, NS : neurosurgery, RM : rehabilitation medicine, CP : critical pathway, QI : quality improvement, DB : database, CT : computed tomography, MRI : magnetic resonance imaging, CTA : CT angiography, MRA : MR angiography, SPECT : single photon-emission CT, PET : positron emission tomography, IV : intravenous, tPA : tissue plasminogen activator, ICP : intracranial pressure, IA : intra-arterial, ICU : intensive care unit 
gions and hospitals; to ensure high quality service in future, it will be necessary to provide resource support consisting of the essential factors identified above, even though treatment results do not currently seem to be affected. In particular, many regional hospitals suffer from a shortage of essential manpower, especially of neurosurgical residents; a countermeasure to this problem is needed, because neurosurgical residents and professional nurses are essential manpower in emergency surgery.

Examples of CSC management from abroad can be used to illustrate the effectiveness of the approach in treating CVD. In the United States, CSCs were proposed by the Brain Attack Coalition (BAC) in $2005^{1)}$; they focused on five main domains, further dividing requirements into essential and optional items (Table 3). Subsequently, CSC became one factor in an advanced program of disease-specific care certification, which has been managed by The Joint Commission since $2007^{7}$. The certification requirements were based on the proposal of BAC; notably, the volume of care became one of the requirements. To qualify for certification, the institute must be capable of managing more than 20 subarachnoid hemorrhage patients, 15 patients undergoing coiling or clipping for intracranial aneurysm, and 25 patients receiving intravenous (IV) tissue plasminogen activator (tPA).

In Japan, a survey of experts similar to the present study was performed in 2007. It defined components as essential if over $75 \%$ of respondents considered them absolutely necessary (Table 4). Based on this survey, a CSC score was awarded to each institution. In addition, the clinical outcomes from 265 institutes were analyzed using the Japanese Diagnosis Procedure Combination Database. A total of 53170 participants were enrolled who had been admitted as emergent patients between April 2010 and March 2011 2). The case mortality rates were $7.8 \%, 16.8 \%$, and $28.1 \%$ for ischemic stroke, intracerebral hemorrhage, and subarachnoid hemorrhage, respectively. Regarding ischemic stroke, the adjusted mortality was correlated with the total CSC score, and with the personnel, infrastructural, and educational scores. Similarly, diagnostic technique, educational, and total CSC scores were correlated with the adjusted mortality of intracerebral hemorrhage patients, and specific expertise, infrastructural, educational, and total CSC scores contributed to mortality in patients with subarachnoid hemorrhage.

This evidence from abroad suggests that CSCs play an im-
Table 4. Essential components proposed by the Japan Stroke Society Expert Survey in 2007

\begin{tabular}{|c|c|}
\hline Domains & Items \\
\hline Personnel & $\begin{array}{l}\text { Neurologists } \\
\text { Neurosurgeons } \\
\text { Endovascular physicians } \\
\text { Critical care medicine } \\
\text { Physical medicine and rehabilitation } \\
\text { Rehabilitation therapy } \\
\text { Stroke rehabilitation nurses }\end{array}$ \\
\hline Diagnostic techniques & $\begin{array}{l}\text { CT } \\
\text { MRI with diffusion } \\
\text { Digital cerebral angiography } \\
\text { CT angiography } \\
\text { Carotid duplex ultrasound } \\
\text { Transcranial Doppler }\end{array}$ \\
\hline Specific expertise & $\begin{array}{l}\text { Carotid endarterectomy } \\
\text { Clipping of intracranial aneurysm } \\
\text { Hematoma removal/draining } \\
\text { Coiling of intracranial aneurysm } \\
\text { Intra-arterial reperfusion therapy }\end{array}$ \\
\hline Infrastructure & $\begin{array}{l}\text { Stroke unit } \\
\text { Intensive care unit } \\
\text { Operating room staffed } \\
\text { Interventional services coverage } \\
\text { Stroke registry }\end{array}$ \\
\hline Education & $\begin{array}{l}\text { Community education } \\
\text { Professional education }\end{array}$ \\
\hline
\end{tabular}

$\mathrm{CT}$ : computed tomography, $\mathrm{MRI}$ : magnetic resonance imaging

portant role in improving the mortality rate of stroke. However, surgical treatment of CVD (cerebrovascular surgery), is currently somewhat neglected by national policy. One related representative national project- the Regional Cardio-cerebrovascular Disease Center Installation and Management Project-focuses on medical treatment of CVD (especially IVtPA); it meets the standard of a Primary Stroke Center in the United States. Such regional cardio-cerebrovascular disease center projects resolve the regional imbalance in medical cerebrovascular treatment and illustrate advances in national stroke treatment. However, surgical cerebrovascular treatment is still inadequate : regional imbalances are not being addressed, and national policies for improvement and level advancement are still not enforced.

\section{CONCLUSION}

As evidenced by the instances abroad, raising the compre- 
hensiveness of treatment at a regional level lowers death rate, incidence of relapse, and complications; therefore, it lowers the national disease burden. Policies should be drafted regarding comprehensive treatment that includes surgery for cerebrovascular disease, and related support plans should be implemented. Specifically, the essential manpower and equipment proposed in this study should be supported regionally. Furthermore, authorities should examine the validity of support using an authentication system within the regional cerebrovascular surgery centers.

\section{CONFLICTS OF INTEREST}

No potential conflict of interest relevant to this article was reported.

\section{INFORMED CONSENT}

Informed consent was obtained from all individual participants included in this study.

\section{References}

1. Alberts MJ, Latchaw RE, Selman WR, Shephard T, Hadley MN, Brass LM, et al. : Recommendations for comprehensive stroke centers: a consensus statement from the Brain Attack Coalition. Stroke 36 : 1597-1616, 2005

2. lihara K, Nishimura K, Kada A, Nakagawara J, Ogasawara K, Ono J, et al. : Effects of comprehensive stroke care capabilities on in-hospital mortality of patients with ischemic and hemorrhagic stroke: J-ASPECT study. PLoS One 9 : e96819, 2014

3. Korean Statistical Information Service : Mortality statistics 2014. Available at : http://kosis.kr/eng/statisticsList/statisticsList_01List. jsp?vwcd=MT_ETITLE\&parentld=D

4. Langhorne P, Fearon P, Ronning OM, Kaste M, Palomaki H, Vemmos K, et al. : Stroke unit care benefits patients with intracerebral hemorrhage: systematic review and meta-analysis. Stroke 44 : 3044-3049, 2013

5. Ministry of Health and Welfare : National Health Plan 2020. Available at : http://www.mohw.go.kr/front_new/jb/sjb030301vw.jsp?PAR_ MENU_ID=03\&MENU_ID=0319\&CONT_SEQ=257824

6. Organization for Economic Co-operation and Development : OECD Health Data 2011. Available at : http://dx.doi.org/10.1787/888932523367

7. Joint Commission launches two new disease-specific care certification programs. Jt Comm Perspect 26 : 1, 11, 2006 